ELECTRONIC LETTER

\title{
Genetic evidence for CFTR dysfunction in Japanese: background for chronic pancreatitis
}

\author{
K Fujiki, H Ishiguro, S BH Ko, N Mizuno, Y Suzuki, T Takemura, A Yamamoto, T Yoshikawa, \\ M Kitagawa, T Hayakawa, Y Sakai, T Takayama, M Saito, T Kondo, S Naruse
}

J Med Genet 2004;41:e55 (http://www.jmedgenet.com/cgi/content/full/41/5/e55). doi: 10.1136/jmg.2003.014456

T e cystic fibrosis transmembrane conductance regulator (CFTR) is a cAMP regulated $\mathrm{Cl}^{-}$channel that is expressed in many epithelial tissues. ${ }^{1}$ In the pancreas CFTR plays a key role in the apical $\mathrm{HCO}_{3}{ }^{-}$transport in duct cells. ${ }^{2-5}$ Loss of its function due to mutations in the CFTR gene causes cystic fibrosis (CF) of the pancreas with exocrine insufficiency, chronic airway disease, and abnormally elevated sweat chloride concentration. Over 1000 mutations and 200 polymorphic loci in CFTR have now been identified. ${ }^{6}$ These mutations and polymorphisms confer quite variable phenotypes from classic CF to atypical CF with less severe pulmonary lesions, pancreatic sufficiency, and normal or borderline sweat chloride concentration. ${ }^{78}$ It is now well recognised that the spectrum of CFTR related disease is much broader than previously thought.' Some individuals may exhibit an apparently single clinical feature or a monosymptomatic disease, such as chronic sinusitis, congenital bilateral absence of the vas deferens (CBAVD), and sweat chloride abnormalities. Recent evidence ${ }^{10-12}$ suggests that chronic pancreatitis, in at least a subset of the patients, belongs to this group of disease. ${ }^{13}$

Chronic pancreatitis is a progressive inflammatory disease of the pancreas that causes the loss of pancreatic acinar cells, ductal abnormalities often with intraductal stones, and irregular fibrosis. Alcohol is the most common cause of chronic pancreatitis in men but idiopathic pancreatitis is more common in women. The incidence of chronic pancreatitis in Western countries (about 4 per 100000 population) is similar to that (5.4-5.9 per 100000$)$ in Japan. ${ }^{14}$ However, the incidence of CF in Japanese is very low ( 1 per 350 000) compared with whites (1 per 2500 live births)..$^{75}$ The apparent large difference of the incidence of CF and chronic pancreatitis may not support the presence of CFTR dysfunction in Japanese. However, earlier studies in France ${ }^{16}$ and Japan, ${ }^{17}$ and our recent study ${ }^{18}$ demonstrated that patients with chronic pancreatitis have high sweat chloride concentration, indicating the presence of CFTR dysfunction in both French and Japanese.

There are few data on CFTR in Asia, ${ }^{6}$ except for sporadic reports on CFTR mutations of CF patients. Some polymorphic loci may affect transcription or function of the CFTR protein. For example, polythymidine (poly-T) and TG dinucleotide repeats, (TG)n, at the junction of intron 8 and exon 9 influence transcription and thereby reduce the amount of normal CFTR protein. ${ }^{19}{ }^{20}$ The $\mathrm{M} / \mathrm{V}$ polymorphism at position 470 affects the function of the CFTR protein..$^{20}$ In order to understand the genetic background for CFTR dysfunction in chronic pancreatitis in Japanese, we first analysed patients with chronic pancreatitis and healthy individuals for $20 \mathrm{CF}$ mutations that are common in whites, along with $9 \mathrm{CF}$ causing and 2 other non-CF causing (Q1352H and R1453W) mutations commonly found in Japanese. We then analysed polymorphisms of poly-T, TG repeats, and M470V and found a unique evolution of the CFTR gene in Japanese that results

\section{Key points}

- None of the 20 common CFTR mutations in white populations and the 9 mutations causing cystic fibrosis in Japanese was found in 162 normal subjects and 65 patients with (51 alcoholic and 14 idiopathic) chronic pancreatitis.

- Compared with whites, Japanese subjects had a higher frequency of the (TG)12 polymorphism, with a (TG) 11:(TG)12 ratio of roughly 1:1. The frequency of the (TG) $12 / 12$ in alcoholic pancreatitis (35\%) was significantly $(p=0.038)$ higher than in controls.

- Genotype analysis revealed two major haplotypes, the (TG) 12-M470 (31\%) and (TG)11-V470 (51\%); the former was known to express a smaller amount of intact CFTR proteins and the latter to produce proteins with lower intrinsic activity.

- These genetic backgrounds, together with a high association of Q1352H (12.3\% in chronic pancreatitis patients $v 3.7 \%$ in controls) or R1453W (6.2\% v 3.1\%), may explain the association of CFTR dysfunction and chronic pancreatitis in Japan where CF is very rare.

in decreased production of intact CFTR proteins or in proteins with lower intrinsic channel activity.

\section{MATERIALS AND METHODS \\ Subjects}

This study was approved by the ethical committee of Nagoya University Graduate School of Medicine and written informed consent was obtained from each subject prior to the study. Fifty one patients with alcoholic chronic pancreatitis (47 males, 4 females; mean age 61 years, range 27-82, 14 patients with idiopathic chronic pancreatitis (11 males, 3 females; mean age 57 years, range 13-85), and 162 normal subjects (142 males, 20 females; mean age 56 years, range 22-87), participated in this study. Diagnosis of chronic pancreatitis was based on the criteria of the Japanese Pancreas Society, 1995: ${ }^{21}$ the presence of the intraductal calcification $(\mathrm{n}=61)$, abnormal pancreatic ducts by endoscopic retrograde cholangiopancreatography $(n=57)$, or decreased exocrine pancreatic secretion by secretin test $(n=46)$. Patients who consumed ethanol over $60 \mathrm{~g} / \mathrm{day}$ for more than 10 years were considered alcoholic. Patients with

Abbreviations: $C B A V D$, congenital bilateral absence of the vas deferens; CF, cystic fibrosis; CFTR, cystic fibrosis transmembrane conductance regulator 
no or occasional social alcohol intake were classified as idiopathic following the exclusion of known rare causes of chronic pancreatitis.

\section{DNA analysis}

Genomic DNA was extracted from blood leukocytes using the QiaAmp DNA Blood Mini kit (Qiagen, Hilden, Germany). PCR was carried out using ExTaq (TaKaRa, Japan). The PCR protocol was 35 cycles using a GeneAmp PCR system (model 9700; Applied Biosystems, Foster, CA, USA) at $94^{\circ} \mathrm{C}$ for 30 seconds, $60^{\circ} \mathrm{C}$ for 60 seconds, and $72^{\circ} \mathrm{C}$ for 30 seconds. The oligonucleotide primers used were: intron 6 a sense $5^{\prime}$ TGGAATGAGTCTGTACAGCG-3', antisense 5'-GAGGTGGAA GTCTACCATGA-3'; intron 8 and exon 9 junction sense $5^{\prime}$ -

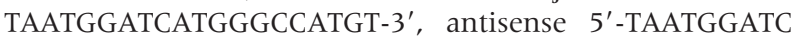
ATGGGCCATGT-3'; and exon 10 sense 5'-TTGTGCATAGCA GAGTACCTGAAA-3', antisense 5'-GCTTCTTAAAGCATA GGTCATGTG-3'. PCR products were purified using the High Pure PCR Product Purification kit (Roche Diagnostics, Mannheim, Germany) and sequenced directly by an automated sequencer (ABI 310) using a dGTP BigDye ${ }^{\mathrm{TM}}$ Terminator Ready Reaction kit (Applied Biosystems). The M470V mutation was detected by HphI restriction enzyme digestion. The 20 most common CF mutations (E60X, Rl17H, R334W, R347P, A455E, $\Delta \mathrm{I} 507, \Delta \mathrm{F} 508, \mathrm{G} 542 \mathrm{X}, \mathrm{G} 551 \mathrm{D}, \mathrm{R} 553 \mathrm{X}$, $621+1 G \rightarrow T, 1078 d e l T, R 1162 X, S 1251 N$, Wl282X, N1303K, $1717-1 \mathrm{G} \rightarrow \mathrm{A}, 2183 \mathrm{AA} \rightarrow \mathrm{G}, 3659 \mathrm{delC}$, and $3849+10 \mathrm{kbC} \rightarrow \mathrm{T})$ were tested by an Elucigene CF20 kit (AstraZeneca Diagnostics, Abingdon, Oxfordshire, UK). The nine CF causing (R75X, Q98R, M152R, R347H, L441P, L571S, D979A, H1085R, and T1086I) and two non-CF causing (Q1352H and R1453W) mutations in Japanese ${ }^{62-24}$ were screened by SNP typing with a Masscode system (Shimadzu, Kyoto, Japan) and confirmed by sequence analysis in positive and equivocal cases.

\section{Haplotype analysis}

Poly-T and (TG)n are continuous in sequence, hence their haplotypes were identified by direct sequence analysis. The frequency of each haplotype of (TG)n and M470V $\left(\mathrm{P}_{\mathrm{m}}\right)$ was estimated by the following equation derived from Hardy-Weinberg's law: $\left(\mathrm{P}_{1}+\mathrm{P}_{2}+\mathrm{P}_{3}+\ldots+\mathrm{P}_{\mathrm{m}}\right)^{2}=1$, where $\mathrm{P}_{1}+\mathrm{P}_{2}+\mathrm{P}_{3}+\ldots+\mathrm{P}_{\mathrm{m}}=1$, and $\mathrm{P}_{1}{ }^{2}, \mathrm{P}_{2}{ }^{2}, \mathrm{P}_{3}{ }^{2}, \ldots, \mathrm{P}_{\mathrm{m}}{ }^{2}$ are the frequencies of homozygous for either locus or both loci.

\section{Statistical analysis}

$\chi^{2}$ test with Yates correction if appropriate was used for statistical analysis and $\mathrm{p}<0.05$ was considered significant.

\section{RESULTS \\ CFTR mutations}

None of the 20 CFTR mutations common in whites and the 9 CF causing mutations in Japanese was found in the total of 454 alleles of 162 normal subjects and 65 patients with chronic pancreatitis. However, Q1352H and R1453W, both of which were originally identified in Japanese patients with diffuse panbronchiolitis, ${ }^{6}$ were found in one allele of both control and patients. Q1352H was found in eight patients with chronic pancreatitis (six alcoholic and two idiopathic); the frequency of Q1352H in chronic pancreatitis (12.3\%) was significantly $(\mathrm{p}=0.015)$ higher than that of controls $(3.7 \%$; 6 in 162 subjects). R1453W was present in five controls (3.1\%) and four patients $(6.2 \%)$ with chronic pancreatitis (two alcoholic and two idiopathic) but their frequencies were not significantly $(p=0.281)$ different. One patient with idiopathic chronic pancreatitis was homozygous for R1453W.
Table 1 Allele frequency of poly-T

\begin{tabular}{|c|c|c|c|c|c|}
\hline & \multirow{2}{*}{$\begin{array}{l}\text { No. of } \\
\text { alleles }\end{array}$} & \multicolumn{4}{|c|}{ No. $(\%)$ of poly-T found } \\
\hline & & $5 \mathrm{~T}$ & $6 \mathrm{~T}$ & $7 T$ & 9T \\
\hline Normal subjects & 324 & $2(0.6)$ & $4(1.2)$ & $316(97.5)$ & $2(0.6)$ \\
\hline $\begin{array}{l}\text { Chronic } \\
\text { pancreatitis }\end{array}$ & 130 & $2(1.5)$ & $0(0.0)$ & 125 (96.2) & $3(2.3)$ \\
\hline Alcoholic & 102 & $2(2.0)$ & $0(0.0)$ & $97(95.1)$ & $3(2.9)$ \\
\hline Idiopathic & 28 & $0(0.0)$ & $0(0.0)$ & $28(100.0)$ & $0(0.0)$ \\
\hline
\end{tabular}

\section{Polymorphisms}

Poly-T

The $7 \mathrm{~T}$ was the most common (97.5\%) haplotype and hence the $7 \mathrm{~T} / 7 \mathrm{~T}$ was a dominant genotype in Japanese (table 1). Compared with whites, the 5T and 9T were very rare. The 5T was found in only two normal subjects and two patients with alcoholic pancreatitis. Four alleles of 6T were newly found in normal subjects. The sequence analysis indicates that three alleles of 6T probably resulted from a deletion of thymidine from the 7T and the other one by a point mutation from $\mathrm{T}$ to A. The frequency distribution of poly- $\mathrm{T}$ in alcoholic or idiopathic chronic pancreatitis was not different from that in normal subjects.

\section{TG repeats}

The (TG)11 and (TG)12 were dominant haplotypes in Japanese and the ratio was roughly 1:1 (table 2). Their frequency in chronic pancreatitis was similar to that in normal subjects. However, the frequency distributions of genotypes of (TG)11/11, (TG)11/12, and (TG)12/12 were significantly $(\mathrm{p}=0.044)$ different among normal subjects and patients with alcoholic and idiopathic pancreatitis (fig l). The relative ratios of the (TG) $11 / 11$, (TG) $11 / 12$, and (TG) 12 / 12 were roughly $1: 2: 1$ in normal subjects, $1: 2: 2$ in alcoholic pancreatitis, and 2:1:2 in idiopathic pancreatitis. The frequency of the (TG) $12 / 12$ in alcoholic pancreatitis (35\%) was significantly $(p=0.038)$ different from the normal control $(20 \%)$.

\section{M470V}

The ratio of methionine $(\mathrm{M})$ and valine $(\mathrm{V})$ at position 470 in exon 10 was 2:3 in normal subjects (table 3 ). The frequencies of $\mathrm{M}$ and $\mathrm{V}$ haplotypes in chronic pancreatitis were not significantly different from those in normal subjects. However, the frequency distribution of $\mathrm{M} / \mathrm{M}, \mathrm{M} / \mathrm{V}$, and $\mathrm{V} / \mathrm{V}$ genotypes in alcoholic pancreatitis did not fit HardyWeinberg distribution because of the higher $(\mathrm{p}<0.05)$ frequency of the $\mathrm{M} / \mathrm{M}$ genotype.

\section{Linkage of GATT repeats, M470V, and TG repeats}

As shown in table 4, all the (GATT)6 and (GATT) 7 repeats were associated with M470 and V470, respectively. By comparing the genotypes of (GATT)6/6-M/M470 and (GATT)7/7-V/V470 with TG repeats, five haplotypes, (GATT)6-(TG)11-M470, (GATT)6-(TG)12-M470,

Table 2 Allele frequency of TG repeats

\begin{tabular}{lrlllll}
\hline & No. of & \multicolumn{4}{l}{ No. (\%) of TG found } \\
\cline { 3 - 6 } & alleles & TG10 & TG11 & TG12 & TG13 \\
\hline Normal subjects & 324 & $0(0)$ & $165(51)$ & $156(48)$ & $3(1)$ \\
Chronic pancreatitis & 130 & $1(1)$ & $57(44)$ & $71(55)$ & $1(1)$ \\
Alcoholic & 102 & $1(1)$ & $42(41)$ & $58(57)$ & $1(1)$ \\
Idiopathic & 28 & $0(0)$ & $15(54)$ & $13(46)$ & $0(0)$ \\
\hline
\end{tabular}




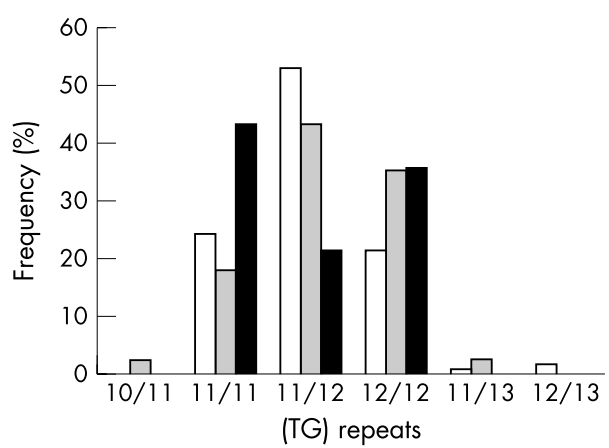

Figure 1 Frequency distribution of genotypes of TG repeats expressed as $\%$ of the total. White bars are 162 normal subjects, grey bars are 51 alcoholic pancreatitis, and black bars are 14 idiopathic pancreatitis patients.

(GATT)7-(TG) 11-V470, (GATT)7-(TG) 12-V470, and (GATT)7(TG) 13-V470, were identified. The genotypes with M/M470, V/V470, (TG)11/11, and (TG)12/12 could be assigned to each haplotype as shown in fig 2. The (GATT)6-(TG)12M470 is the most common haplotype $(31 \%$ of 184 haplotypes identified) in normal subjects with the $M$ type, and the (GATT)7-(TG)11-V470 is the most common (51\%) in the $\mathrm{V}$ type. Although the exact haplotype assignment in each subject with the (TG)11/12-M/V470 genotype is not possible, based on the above haplotype frequency (fig 2), it can be estimated that most (about 98\%) of them consist of (GATT)6-(TG)12-M470 and (GATT)7-(TG)11-V470.

\section{Association of $5 \mathrm{~T}, \mathrm{Q} 1352 \mathrm{H}$, and R1453W with genotypes of (TG)m/n-M470V}

Fig 3 summarises the frequency distribution of normal subjects and patients with chronic pancreatitis based on the genotypes of the TG repeats and M470V. 5T was associated with (TG) $12 / 13-M / V 470$ in two normal subjects and with (TG) $12 / 12-M / V 470$ in two alcoholic patients. Q1352H was present in patients with (TG)11/11-V/V470 (three alcoholic and two idiopathic), (TG)11/12-M/V470 (6 normal and 2 alcoholic), and (TG)11/12-V/V470 (one alcoholic). R1453W was found in five normal subjects with (TG) $11 / 11-V / V 470$ $(\mathrm{n}=3)$, (TG) 11/12-M/V470 $(\mathrm{n}=1)$, and $(\mathrm{TG}) 12 / 12-\mathrm{M} / \mathrm{M} 470$ $(\mathrm{n}=1)$, and four patients with (TG)11/11-V/V470 (two alcoholic and two idiopathic).

\section{DISCUSSION}

\section{CFTR mutations}

The present study is the first attempt at a systematic analysis of CFTR in Japanese patients with chronic pancreatitis. As expected from data of genetic analysis of various ethnic groups and a low incidence rate of CF in Japan, the 20 most common European mutations and the 9 CF causing mutations reported in Japanese were not detected. However, we found a significantly higher accumulation (12.3\%) of the Q1352H allele in patients with chronic pancreatitis, though it was also observed in healthy subjects $(3.7 \%$ in Japanese and $0.9 \%$ in Korean). Glutamine at 1352 is located in the second nucleotide binding fold of CFTR, ${ }^{1}$ and its change to histidine (Q1352H) causes reduction in both protein expression and channel activity of CFTR. ${ }^{25}$ This mutation has been found in Japanese patients with CBAVD (25\%), and in Korean patients with chronic pancreatitis (14.3\%) and bronchiectasis $(11.8 \%) .^{25}$ The other mutation, R1463W, affects channel activity but its overall effect on CFTR function appears to be mild. ${ }^{25}$ One patient homozygous for R1453W showed no clinical manifestations other than idiopathic pancreatitis.

\section{Polymorphisms}

In the present study, we found a unique frequency distribution of TG repeats that are known to affect the amount of normal CFTR protein. A TG repeat at the $3^{\prime}$ end of intron 8 of CFTR gene is the binding site of the splicing factors. ${ }^{26}$ The longer TG repeats increase the probability of alternative splicing of exon 9, which results in a production of nonfunctional CFTR protein. ${ }^{27}$ In Greece the frequency of (TG) 12 was higher in patients with disseminated bronchiectasis $(10.5 \%)$ and asthma $(12.5 \%)$ than in the general population $(1 \%) .^{28}$ Although Japanese individuals had a higher frequency of the (TG)12 repeat (table 2) compared with Europeans, ${ }^{28} 29$ the proportion of the (TG)12/12 genotype was higher in patients with alcoholic pancreatitis than normal subjects (fig 1 ). M470V is a common polymorphism in exon 10 in CFTR, which affects intrinsic chloride channel activity; M470 CFTR proteins had a 1.7-fold activity of V470 CFTR proteins. ${ }^{20}$ Simple comparisons of haplotypes and genotypes of M470V alone showed no significant difference between chronic pancreatitis and normal subjects (table 3 ). We found four alleles of $6 \mathrm{~T}(1.2 \%)$ in normal subjects. The $6 \mathrm{~T}$ repeat has not been reported in whites ${ }^{6}$ but was recently found in a Korean patient with bronchiectasis. ${ }^{25}$ As the 6T was found only in normal subjects in our study, it is probably not related to chronic pancreatitis.

\section{Evolution of (TG)n-M470V}

Haplotype analysis revealed an interesting association of (TG)n and M470V (fig 2). The (TG)n locus is present only in primates; the repeat length is seven in Pan troglodytes (AC087834) and nine in macaques (AC123966, AF162160, AF162383, AFl62356). The shortest length observed in humans is eight, ${ }^{29}$ though it is very rare. Hence the shorter repeat haplotype, (GATT)6-(TG)10-M470, probably evolved to (GATT)6-(TG)12-M470 by a stepwise slippage of TG. ${ }^{30}$ Similarly, the (GATT)7-(TG)11-V470 probably evolved to (GATT)7-(TG)13-V470. As (TG)10 and (TG)11 in the M haplotype were very rare in the Japanese subjects, selection must have favoured the (TG) 12 genotype that produces a decreased amount of CFTR protein with high intrinsic activity. This process, however, was not favoured in the $\mathrm{V}$ haplotype with low intrinsic activity, because the majority of these ( 51 in 68 alleles) remained as the initial haplotype and only $23 \%$ and $0.8 \%$ proceeded to (TG) 12 and (TG) 13 , respectively.

Table 3 Frequency of M470V

\begin{tabular}{|c|c|c|c|c|c|c|}
\hline & \multirow[b]{2}{*}{$\mathrm{n}$} & \multicolumn{5}{|c|}{ No. $(\%)$ of haplotypes } \\
\hline & & $M / M$ & $M / V$ & $\mathrm{~V} / \mathrm{V}$ & M & v \\
\hline Normal subjects & 162 & $24(15)$ & $82(51)$ & $56(35)$ & $130(40)$ & $194(60)$ \\
\hline Chronic pancreatitis & 65 & $17(26)$ & $25(38)$ & $23(35)$ & $59(45)$ & 71 (55) \\
\hline Alcoholic & 51 & $14(27)$ & 21 (41) & $16(31)$ & $49(48)$ & $53(52)$ \\
\hline Idiopathic & 14 & $3(21)$ & $4(29)$ & $7(50)$ & $10(36)$ & $18(64)$ \\
\hline
\end{tabular}


Table 4 Linkage of (GATT) repeats, M470V, and TG repeats

\begin{tabular}{|c|c|c|c|c|c|}
\hline \multicolumn{3}{|l|}{ Repeats } & \multirow{2}{*}{$\begin{array}{l}\text { Normal subjects } \\
(n=162)\end{array}$} & \multicolumn{2}{|c|}{ Chronic pancreatitis, no. (\%) } \\
\hline (GATT)n & M470V & $(\mathrm{TG}) \mathrm{n}$ & & Alcoholic ( $n=51$ ) & Idiopathic $(n=14)$ \\
\hline $6 / 6$ & $M / M$ & $11 / 12$ & $0(0)$ & $2(4)$ & $0(0)$ \\
\hline $6 / 6$ & $M / M$ & $12 / 12$ & $24(15)$ & $12(24)$ & $3(21)$ \\
\hline $6 / 7$ & $M / V$ & $10 / 11$ & $0(0)$ & $1(2)$ & $0(0)$ \\
\hline $6 / 7$ & $M / V$ & $11 / 11$ & $3(2)$ & $0(0)$ & $0(0)$ \\
\hline $6 / 7$ & $M / V$ & $11 / 12$ & $68(42)$ & $14(27)$ & $2(14)$ \\
\hline $6 / 7$ & $M / V$ & $11 / 13$ & $0(0)$ & $1(2)$ & $0(0)$ \\
\hline $6 / 7$ & $M / V$ & $12 / 12$ & $9(6)$ & $5(10)$ & $2(14)$ \\
\hline $6 / 7$ & $M / V$ & $12 / 13$ & $2(1)$ & $0(0)$ & $0(0)$ \\
\hline $7 / 7$ & $\mathrm{~V} / \mathrm{V}$ & $11 / 11$ & $36(22)$ & $9(18)$ & $6(43)$ \\
\hline $7 / 7$ & $\mathrm{~V} / \mathrm{V}$ & $11 / 12$ & 18 (11) & $6(12)$ & $1(7)$ \\
\hline $7 / 7$ & $\mathrm{~V} / \mathrm{V}$ & $11 / 13$ & 1 (1) & $0(0)$ & $0(0)$ \\
\hline $7 / 7$ & $\mathrm{~V} / \mathrm{V}$ & $12 / 12$ & $1(1)$ & $1(2)$ & $0(0)$ \\
\hline
\end{tabular}

When the haplotype frequencies of (TG)n-M470V were compared, there was a marked difference between Japanese and European populations; about $70 \%$ of the $\mathrm{M}$ haplotype in Greek and French individuals was (TG)10-M470, and haplotypes with (TG) 11 and (TG) 12 were about 30\% and $3 \%$, respectively. ${ }^{28}{ }^{29}$ Furthermore, (TG) 10-V470, which was not detected in Japanese in this study, occupies $8 \%$ and $16 \%$ of the $\mathrm{V}$ haplotype in Greece and France. Thus after separation from the white ancestors, the Japanese ancestors had received higher selective pressure for longer TG repeats or lower expression of CFTR proteins.

What was the selection pressure for Japanese? In Asia, Africa, and Latin America, infectious diarrhoeal diseases are the major cause of mortality in children. Even today more than three million children die per year from diarrhoea related disease, about half of which are due to bacterial toxins. ${ }^{31}$ Cholera toxin, and heat labile and heat stable enterotoxins produced by intestinal pathogenic Escherichia coli cause secretory diarrhoea via the activation of the CFTR chloride channel. ${ }^{32}$ Hence, decreased production of intact CFTR proteins in the (TG) 12/12 genotype compared with the (TG) 10/10, 10/11, and 11/11 genotypes would lead to less fluid loss and help survival in diarrhoeal diseases. Why was this selection pressure less prominent in the $\mathrm{V} / \mathrm{V}$ genotype compared with the M/M genotype? Sweat $\mathrm{Cl}^{-}$and fluid reabsorption is smaller and, therefore, fluid loss via sweating is larger in individuals with the V/V genotype with lower CFTR chloride channel activity. One may speculate that increased sweat fluid and electrolyte loss is another selective pressure in the warm and humid climate of Japan, where thermoregulation by sweating is of vital importance. ${ }^{31}$ Further analysis of other Asian populations is required to test the validity of this hypothesis.

\section{CFTR function predicted by genotypes}

The overall CFTR function in vivo is determined by its genotype. Based on the TG repeats, which determine the level of functional CFTR protein, and M470V, which determines intrinsic chloride channel activity, the genotypes of CFTR in Japanese can arbitrarily be classified into nine groups (fig 3). The genotypes that produce proteins with higher CFTR function, such as M/M470 with (TG) $11 / 11$ or $11 / 12$ and M/ V470 with (TG)11/11, were either absent or significantly smaller in Japanese, while a considerable number of these genotypes were present in Greek and French individuals (fig 2). Most M/M470 genotypes were associated with (TG) $12 / 12$, which reduces the amount of intact CFTR proteins from both genes. In the genotype (TG)11/11-V/V470, both genes express proteins with low intrinsic channel activity. Most $(98 \%)$ of the M/V470 genotypes consisted of the (TG) 12-M470 and (TG)11-V470 haplotypes, which result in lower CFTR function owing to a decrease in the amount of intact protein from one gene and lower intrinsic channel activity of the protein coded by the other. Hence, the majority of Japanese (about 97\%) have genotypes that cause lower CFTR function.

Although genotyping based on the TG repeats and M470V alone is not sufficient to explain the association of chronic pancreatitis and CFTR, an additional mild mutation or polymorphism on these genetic backgrounds may further

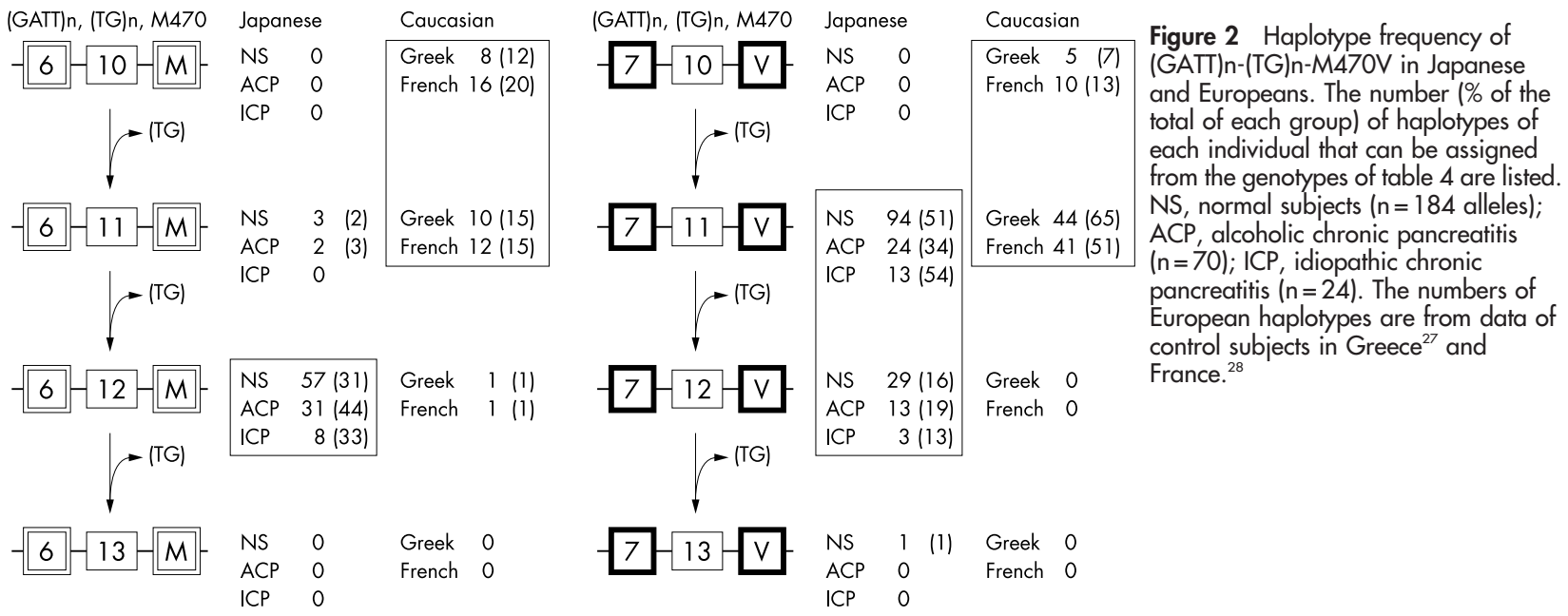




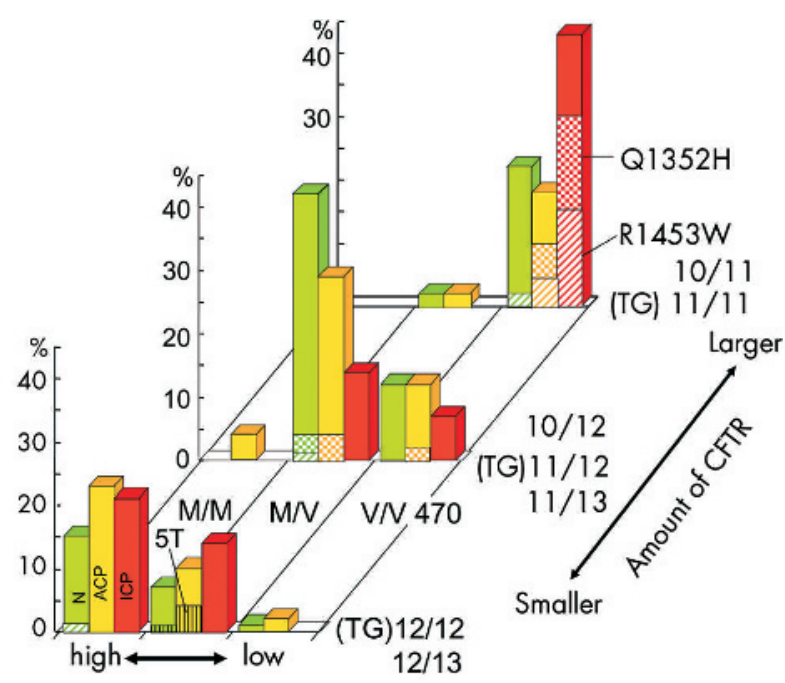

Intrinsic activity of CFTR

Figure 3 The frequency (\% of the total of each group) of each of nine genotypes classified based on the TG repeats and M470V. N (green column), 162 normal subjects; ACP (yellow column), 51 alcoholic chronic pancreatitis; and ICP (red column), 14 idiopathic chronic pancreatitis. The associated $5 \mathrm{~T}, \mathrm{Q} 1352 \mathrm{H}$, and R1453W are overlaid on each column.

reduce CFTR function. Indeed, the Q1352H allele was found in three alcoholic and two idiopathic pancreatitis patients with the (TG)11/11-V/V470 haplotype (fig 3). This mutation, when expressed in $\mathrm{CHO}$ cells, reduces both protein expression and channel activity by about $70 \%$. The $\mathrm{Cl}^{-}$channel activity is almost completely abolished in cells that expressed the V470-Q1352H CFTR. ${ }^{25}$ As Q1352H was always present in the V470 background, this allele cannot produce functional CFTR proteins. Thus, we can estimate that the association of Q1352H in the V/V470 genotype reduces the total CFTR function to about $25 \%$ of the wild type. R1453W may not cause CF related disease by itself but its association in the $\mathrm{V} / \mathrm{V}$ genotype may reduce the total CFTR function to less than $50 \%$. The $5 \mathrm{~T}$ repeat often occurred in cis with (TG) 12 or (TG) 13 in idiopathic pancreatitis. ${ }^{12}{ }^{33}$ In the present study two normal individuals had the (TG)13-5T haplotype and two patients with alcoholic pancreatitis had the (TG) 12-5T. This association will cause greater loss of functional CFTR protein than either polymorphism alone.

It is not known whether specific genotypes of CFTR determine the susceptibility to either alcoholic or idiopathic pancreatitis. We have recently found that ethanol at concentrations observed after moderate drinking causes a considerable change in fluid and electrolyte transport in pancreatic duct cells, presumably via CFTR. ${ }^{34}$ As CFTR has multiple regulatory functions other than chloride channel regulation, it remains to be determined as to which of its functions is most important in the pathogenesis of alcoholic and idiopathic chronic pancreatitis.

In summary we have observed a unique evolution of CFTR in Japanese that results in two major haplotypes, the (TG) 12M470 and (TG)11-V470. The former was known to express a smaller amount of intact CFTR proteins and the latter to produce proteins with lower intrinsic activity. Therefore, CFTR function predicted from the genotypes in the majority of Japanese is lower than that in whites with wild type CFTR genes. Association of other mutations, such as Q1352H and R1453W, may further reduce CFTR function. These genetic backgrounds probably explain the association of CFTR dysfunction and chronic pancreatitis in Japan where CF or mutations causing CF are very rare compared with chronic pancreatitis. It remains to be studied how this mild CFTR dysfunction increases the risk of chronic pancreatitis.

\section{ACKNOWLEDGMENTS}

This work was supported by grants from the Uehara Memorial Foundation, Pancreas Research Foundation of Japan, the Japanese Society for the Promotion of Science, and the Ministry of Health, Labour and Welfare, Japan. S B H Ko is a research fellow of the Japanese Health Sciences Foundation. We thank Ms Y Kuroyanagi and M Nakakuki for their technical assistance and Drs V Wray and K Fujiki for their advice.

\section{Authors' affiliations}

K Fujiki, H Ishiguro, T Kondo, Department of Human Nutrition, Nagoya University, Nagoya, Japan

H Ishiguro, S B H Ko, N Mizuno, Y Suzuki, T Takemura, A Yamamoto, T Yoshikawa, M Kitagawa, T Hayakawa, S Naruse, Department of Internal Medicine, Nagoya University, Nagoya, Japan

Y Sakai, T Takayama, Sakashita Hospital, Gifu, Japan

M Saito, Chybu Health Care Center, Nagoya, Japan

Conflicts of interest: none declared

Correspondence to: Dr S Naruse, Department of Internal Medicine, Graduate School of Medicine, Nagoya University, 65 Tsurumaicho, Showa-ku, Nagoya 466-8550, Japan; snaruse@med.nagoya-u.ac.jp

Revised version received 4 November 2003

Accepted for publication 14 November 2003

\section{REFERENCES}

1 Riordan JR, Rommens JM, Kerem B, Alon N, Rozmahel R, Grzelczak Z, Zielenski J, Lok S, Plavsic N, Chou JL, Drumm ML, lannuzzi MC, Collins FS, Tsui LC. Identification of the cystic fibrosis gene: cloning and characterization of complementary DNA. Science 1989;245:1066-73.

2 Case RM, Argent BE. Pancreatic duct cell secretion: control and mechanisms of transport. In: Go VLW, DiMagno EP, Gardner JD, Lebenthal E, Reber HA, Scheele GA, eds. The pancreas: biology, pathobiology, and disease, 2nd edn. New York: Raven Press, 1993:1041-81.

3 Choi JY, Muallem D, Kiselyov K, Lee MG, Thomas PJ, Muallem S. Aberrant CFTR-dependent HCO3- transport in mutations associated with cystic fibrosis. Nature 2001;410:94-7.

4 Ishiguro H, Steward MC, Sohma Y, Kubota T, Kitagawa M, Kondo T, Case RM, Hayakawa T, Naruse S. Membrane potential and bicarbonate secretion in isolated interlobular ducts from guinea-pig pancreas. J Gen Physiol 2002;120:617-28.

5 Ko SB, Shcheynikov N, Choi JY, Luo X, Ishibashi K, Thomas PJ, Kim JY, Kim KH, Lee MG, Naruse S, Muallem S. A molecular mechanism for aberrant CFTR-dependent $\mathrm{HCO}_{3}{ }^{-}$transport in cystic fibrosis. $E M B O J$ 2002;21:5662-72.

6 Cystic Fibrosis Genetic Analysis Consortium, 2003. Available at http://www/ genet sickkids.on.ca/cftr/

7 Zielenski J, Tsui LC. Cystic fibrosis: genotypic and phenotypic variations. Ann Rev Genet 1995;29:777-807.

8 Rosenstein BJ, Cutting GR. The diagnosis of cystic fibrosis: A consensus statement. J Pediatr 1998;132:589-95.

9 Knowles MR, Durie PR. What is cystic fibrosis? N Engl J Med 2002;347:439-42.

10 Sharer N, Schwarz M, Malone G, Howarth A, Painter J, Super M, Braganza J. Mutations of the cystic fibrosis gene in patients with chronic pancreatitis. N Engl J Med 1998;339:645-52.

11 Cohn JA, Friedman KJ, Noone PG, Knowles MR, Silverman LM, Jowell PS Relation between mutations of the cystic fibrosis gene and idiopathic pancreatitis. N Engl J Med 1998;339:653-8.

12 Noone PG, Zhou Z, Silverman LM, Jowell PS, Knowles MR, Cohn JA. Cystic fibrosis gene mutations and pancreatitis risk: relation to epithelial ion transport and trypsin inhibitor gene mutations. Gastroenterology 2001;121:1310-19.

13 Naruse S, Kitagawa M, Ishiguro H, Fujiki K, Hayakawa T. Cystic fibrosis and related diseases of the pancreas. Best Pract Res Clin Gastroenterol 2002;16:511-26.

14 Otsuki M. Chronic pancreatitis in Japan: epidemiology, prognosis, diagnostic criteria, and future problems. J Gastroenterol 2003;38:315-26.

15 Yamashiro Y, Shimizu T, Oguchi S, Shioya T, Nagata S, Ohtsuka Y. The estimated incidence of cystic fibrosis in Japan. J Pediatr Gastr Nutr 1997;24:544-7.

16 Sarles H, Muratore R, Sarles JC, Gaini M, Camette R, Pastor J, Guien C. Aetiology and pathology of chronic pancreatitis. Bibl Gastroent 1965;7:75-120.

17 Hanawa M, Takebe T, Takahashi S, Koizumi M, Endo K. The significance of the sweat test in chronic pancreatitis. Tohoku J Exp Med 1978;125:59-69. 
18 Naruse $\mathrm{S}$, Ishiguro $\mathrm{H}$, Suzuki $\mathrm{Y}$, Fujiki $\mathrm{K}$, Ko $\mathrm{SBH}$, Mizuno $\mathrm{N}$, Takemura $\mathrm{T}$ Yamamoto A, Yoshikawa T, Jin C, Suzuki R, Kitagawa M, Tsuda T, Kondo T, Hayakawa T. A finger sweat chloride test for the detection of the high-risk group of chronic pancreatitis. Pancreas 2003;28:in press.

19 Chu CS, Trapnell BC, Curristin S, Cutting GR, Crystal RG. Genetic basis of variable exon 9 skipping in cystic fibrosis transmembrane conductance regulator mRNA. Nat Genet 1993;3:151-6.

20 Cuppens $H$, Lin W, Jaspers $M$, Costes B, Teng $H$, Vankeerberghen A, Jorissen M, Droogmans G, Reynaert I, Goossens M, Nilius B, Cassiman JJ. Polyvariant mutant cystic fibrosis transmembrane conductance regulator genes. The polymorphic (TG)m locus explains the partial penetrance of the T5 polymorphism as a disease mutation. J Clin Invest 1998;101:487-96.

21 Homma T. Criteria for pancreatic disease diagnosis in Japan: diagnostic criteria for chronic pancreatitis. Pancreas 1998;16:250-4.

22 Hojo S, Fujita J, Miyawaki H, Obayashi Y, Takahara J, Bartholomew DW. Severe cystic fibrosis associated with a F508/R347H+D979A compound heterozygous genotype. Clin Genet 1998;53:50-3

23 Yoshimura K, Wakazono Y, lizuka S, Morokawa N, Tada H, Eto Y. A Japanese patient homozygous for the H1085R mutation in the CFTR gene presents with a severe form of cystic fibrosis. Clin Genet 1999;56:173-5.

24 Morokawa N, lizuka S, Tanano A, Katsube A, Muraji T, Eto Y, Yoshimura K. Severe cystic fibrosis in a Japanese girl caused by two novel CFTR (ABCC7) gene mutations: M152R and 1540del10. Hum Mutat 2000;15:485.

25 Lee JH, Choi JH, Namkung W, Hanrahan JW, Chang J, Song SY, Park SW, Kim DS, Yoon JH, Suh Y, Jang IJ, Nam JH, Kim SJ, Cho MO, Lee JE, Kim KH, Lee MG. A haplotype-based molecular analysis of CFTR mutations associated with respiratory and pancreatic diseases. Hum Mol Genet 2003;15:2321-32.

26 Buratti E, Baralle FE. Characterization and functional implications of the RNA binding properties of nuclear factor TDP-43, a novel splicing regulator of CFTR Exon 9. J Biol Chem 2001;276:36337-43.
27 Strong TV Wilkinson DJ, Mansoura MK, Devor DC, Henze K, Yang Y, Wilson JM, Cohn JA, Dawson DC, Frizzell RA, Collins FS. Expression of an abundant alternatively spliced form of the cystic fibrosis transmembrane conductance regulator (CFTR) gene is not associated with a cAMP-activated chloride conductance. Hum Mol Genet 1993:2:225-30.

28 Tzetis M, Efthymiadou A, Strofalis S, Psychou P, Dimakou A, Pouliou E, Doudounakis $S$, Kanavakis E. CFTR gene mutations including three novel nucleotide substitutions and haplotype background in patients with asthma, disseminated bronchiectasis and chronic obstructive pulmonary disease. Hum Genet 2001;108:216-21.

29 Pallares-Ruiz N, Carles S, Des Georges M, Guittard C, Arnal F, Humeau C, Claustres M. Complete mutational screening of the cystic fibrosis transmembrane conductance regulator gene: cystic fibrosis mutations are not involved in healthy men with reduced sperm quality. Human Reproduction 1999;14:3035-40.

30 Levinson G, Gutman GA. Slipped-strand mispairing: a major mechanism for DNA sequence evolution. Mol Biol Evol 1987;4:203-21.

31 Quinton PM. What is good about cystic fibrosis? Curr Biol 1994:4:742-3.

32 Chao AC, de Sauvage FJ, Dong YJ, Wagner JA, Goeddel DV Gardner P. Activation of intestinal CFTR Cl- channel by heat-stable enterotoxin and guanylin via CAMP-dependent protein kinase. $E M B O J$ 1994;13:1065-72.

33 Arduino C, Gallo M, Brusco A, Garnerone S, Piana MR, Di Maggio S, Gerbino Promis G, Ferrone M, Angeli A, Gaia E. Polyvariant mutant CFTR genes in patients with chronic pancreatitis. Clin Genet 1999;56:400-4

34 Yamamoto $A$, Ishiguro $H$, Ko SB, Suzuki A, Wang $Y$, Hamada $H$ Mizuno N, Kitagawa M, Hayakawa T, Naruse S. Ethanol induces fluid hypersecretion from guinea-pig pancreatic duct cells. J Physiol 2003;551:917-26. 